\title{
Fluid balance, intradialytic hypotension, and outcomes in critically ill patients undergoing renal replacement therapy: a cohort study
}

Jonathan A Silversides ${ }^{1,2,3}$, Ruxandra Pinto ${ }^{4}$, Rottem Kuint ${ }^{1}$, Ron Wald ${ }^{5,6}$, Michelle A Hladunewich ${ }^{6,7,8}$, Stephen E Lapinsky ${ }^{1}$ and Neill KJ Adhikari ${ }^{1,8^{*}}$

\begin{abstract}
Introduction: In this cohort study, we explored the relationship between fluid balance, intradialytic hypotension and outcomes in critically ill patients with acute kidney injury (AKI) who received renal replacement therapy (RRT).

Methods: We analysed prospectively collected registry data on patients older than 16 years who received RRT for at least two days in an intensive care unit at two university-affiliated hospitals. We used multivariable logistic regression to determine the relationship between mean daily fluid balance and intradialytic hypotension, both over seven days following RRT initiation, and the outcomes of hospital mortality and RRT dependence in survivors.

Results: In total, 492 patients were included (299 male (60.8\%), mean (standard deviation (SD)) age 62.9 (16.3) years); 251 (51.0\%) died in hospital. Independent risk factors for mortality were mean daily fluid balance (odds ratio (OR) 1.36 per $1000 \mathrm{~mL}$ positive (95\% confidence interval (CI) 1.18 to 1.57), intradialytic hypotension (OR 1.14 per 10\% increase in days with intradialytic hypotension ( $95 \% \mathrm{Cl} 1.06$ to 1.23$)$ ), age (OR 1.15 per five-year increase ( $95 \% \mathrm{Cl} 1.07$ to 1.25$)$ ), maximum sequential organ failure assessment score on days 1 to 7 (OR 1.21 (95\% Cl 1.13 to 1.29)), and Charlson comorbidity index (OR 1.28 (95\% Cl 1.14 to 1.44)); higher baseline creatinine (OR 0.98 per $10 \mu \mathrm{mol} / \mathrm{L}$ (95\% Cl 0.97 to 0.996)) was associated with lower risk of death. Of 241 hospital survivors, 61 (25.3\%) were RRT dependent at discharge. The only independent risk factor for RRT dependence was pre-existing heart failure (OR 3.13 (95\% Cl 1.46 to 6.74$)$ ). Neither mean daily fluid balance nor intradialytic hypotension was associated with RRT dependence in survivors. Associations between these exposures and mortality were similar in sensitivity analyses accounting for immortal time bias and dichotomising mean daily fluid balance as positive or negative. In the subgroup of patients with data on pre-RRT fluid balance, fluid overload at RRT initiation did not modify the association of mean daily fluid balance with mortality.

Conclusions: In this cohort of patients with AKI requiring RRT, a more positive mean daily fluid balance and intradialytic hypotension were associated with hospital mortality but not with RRT dependence at hospital discharge in survivors.
\end{abstract}

\section{Introduction}

Acute kidney injury (AKI) occurs commonly in critical illness, with 4 to $10 \%$ of patients admitted to the intensive care unit (ICU) requiring renal replacement therapy (RRT) [1-3]. In recent studies, the mortality of ICU patients with

\footnotetext{
*Correspondence: neill.adhikari@utoronto.ca

'Interdepartmental Division of Critical Care, University of Toronto, 30 Bond Street, Toronto, ON M5B 1W8, Canada

${ }^{8}$ Department of Critical Care Medicine, Sunnybrook Health Sciences Centre, Room D1.08, 2075 Bayview Avenue, Toronto, ON M4N 3M5, Canada Full list of author information is available at the end of the article
}

AKI requiring RRT has been reported to be 40 to $50 \%[1,4]$. Specific therapeutic options for AKI are lacking, and emphasis has traditionally been placed on maintenance of renal perfusion using intravenous fluids, inotropes, and vasopressors. Fluid loading is advocated, particularly in sepsis-related AKI, to treat possible hypovolaemia, improve cardiac output, and maximise renal blood flow [5]. This practice is largely unsupported by evidence and has been challenged by observations that renal blood flow in sepsis may be normal, elevated or decreased $[1,4,6]$, that the renal resistive index, a measure of renal vascular tone, is 
unchanged in response to fluid challenge in septic patients [5,7], and by numerous observational studies demonstrating an association between fluid overload and mortality in critically ill adults and children with AKI [1-4,8-12]. It is unclear whether this association reflects confounding by greater severity of illness in patients whose intravenous fluid requirements are higher or in whom efforts to remove fluid are poorly tolerated, or whether it simply reflects variation in the timing of RRT initiation. However, variation in the timing of RRT initiation is unlikely to be the sole explanation for the association between fluid overload and mortality, since it has been demonstrated in cohorts that included AKI patients managed without RRT $[9,10]$ and has been noted at time points other than at RRT initiation [10]. It is also unclear whether treatment with diuretics or ultrafiltration is effective in modifying this relationship.

We conducted a cohort study to investigate the relationship between fluid balance and outcome in critically ill patients with AKI requiring RRT. We hypothesised that positive fluid balance and intradialytic hypotension during the first seven days after RRT initiation would be associated with both mortality and RRT dependence at hospital discharge.

\section{Methods}

\section{Design and setting}

This cohort study used data from the Toronto Acute Kidney Injury registry. The registry is a prospectively collected database of patients who started RRT for AKI at two universityaffiliated hospitals (April 2007 to October 2012 at St Michael's Hospital and December 2009 to December 2011 at Sunnybrook Health Sciences Centre, Toronto, ON, Canada) and includes information such as patient demographics, baseline admission characteristics, comorbidities identified in medical records, fluid balance, RRT variables, vital signs during RRT, and outcomes. In both centres, RRT is initiated by the nephrology team in collaboration with the critical care service, according to standard indications; we did not collect data on the specific indication(s) for each patient. Both teams agreed on modality (intermittent hemodialysis or continuous renal replacement therapy, available at both hospitals, or sustained low-efficiency dialysis, available at St Michael's Hospital only) and fluid management goals.

\section{Patients}

We considered patients aged 16 years or older who received RRT for $\geq 2$ days in an ICU at the two study hospitals (including a coronary care unit at St Michael's Hospital) during the time period noted above, and for whom fluid balance data were available for $\geq 1$ day of their ICU stay. Patients were excluded from the registry if RRT was initiated to treat a toxic ingestion, if they had preexisting end-stage renal disease or had received a renal transplant in the year prior to hospital admission.

\section{Definitions}

We defined day 1 as the 24-hour period, or part thereof, on which RRT was initiated. Daily fluid balance was defined as total fluid intake from all sources (intravenous fluids and blood products, enteral and parenteral nutrition, and medications) minus output (urine, ultrafiltrate, output from drains, and gastrointestinal losses). We calculated mean daily fluid balance for the first seven days following RRT initiation, using the number of days with data available if less than seven. Cumulative fluid balance was the total fluid balance between ICU admission and the day of RRT initiation. Fluid overload at RRT commencement was defined as positive cumulative fluid balance $>10 \%$ of admission weight, as in previous studies $[1,4,8,11]$. We did not collect data on type of intravenous fluid used (balanced or unbalanced crystalloids or colloids).

One session of RRT was defined as continuous renal replacement therapy (CRRT) for a 24-hour period or part thereof or one session of either intermittent hemodialysis or sustained low-efficiency dialysis (SLED). Baseline creatinine was defined as premorbid creatinine or the first creatinine during the index hospital admission if premorbid creatinine was unavailable. Intradialytic hypotension was defined for each session of RRT as either the occurrence of mean arterial pressure (MAP) $<65 \mathrm{mmHg}$ or a reduction of $\geq 20 \%$ from the starting MAP, consistent with widely used definitions of absolute [5,13] and relative [14,15] hypotension, and was expressed as a percentage of days (up to seven) with available data. We lacked data on duration of hypotension and frequency of individual episodes, but all patients were in an ICU or coronary care unit, suggesting that hypotension would be recognised and treated promptly. We did not take into consideration the use of vasopressors to prevent or mitigate intradialytic hypotension because we lacked details of vasopressor dosing during RRT; instead, we determined whether patients received any vasopressor support during the first seven days of RRT.

\section{Data collection}

For eligible patients, we abstracted registry data on primary diagnoses, maximum sequential organ failure assessment (SOFA) scores $[6,16]$ on days 1,3 and 5 (where day 1 is the first day of RRT), Charlson comorbidity index $[7,17]$, laboratory values, daily fluid balance data on days 1 to 7, vital signs, receipt of a vasopressor, and outcomes at hospital discharge. We reviewed the registry data for missing or incorrect data items, and sought missing data elements from available patient records.

\section{Statistical analysis and outcomes}

Continuous variables were summarized as mean (standard deviation, SD) or median (quartile 1 (Q1), quartile 3 (Q3)) as appropriate, and discrete variables are presented as frequencies and percentages. 
We constructed logistic regression models for the outcomes of hospital mortality and RRT dependence at hospital discharge in survivors, with mean daily fluid balance, intradialytic hypotension and sex forced into both models. Other covariates were assessed using univariable logistic regression models; selection criteria for covariate inclusion in the final models were univariable $P \leq 0.2$, clinical plausibility, and absence of important multicollinearity $(P<0.8)$. We did not consider interaction terms in the absence of clinically compelling reasons to believe that any covariate would modify the effect of the main exposure variables. We did not consider fluid overload at RRT commencement as an independent variable in the main analyses due to the extent of missing data. Results are expressed as odds ratios (ORs) with 95\% confidence intervals (CIs). We assessed the relationship between continuous covariates and log odds of the outcomes graphically and detected no departures from the assumption of linearity.

We anticipated that the problem of immortal time bias would lead to an overestimation of the strength of the associations between the exposures of mean daily fluid balance and intradialytic hypotension and the outcome of hospital mortality. This bias arises because a patient who survives longer has more time to develop a negative fluid balance and intradialytic normotension $[18,19]$. We addressed this possibility in a sensitivity analysis by adjusting for number of days with available fluid balance data available (up to seven); in this analysis, the main exposures were mean daily fluid balance (as in the primary analysis) and days with intradialytic hypotension (up to seven). This bias would not affect our analysis of RRT dependence in hospital survivors.

We conducted two additional sensitivity analyses. First, we analysed the same two outcomes with the mean daily fluid balance dichotomised as positive or negative. Second, to investigate whether fluid overload at commencement of RRT modified the relationship between mean daily fluid balance and mortality, we constructed a post hoc logistic regression model in the subgroup of patients with data available to calculate fluid overload. We used the same adjustment variables as in the main model but also adjusted for fluid overload prior to RRT, dichotomised as $>10 \%$ vs. $\leq 10 \%$, and the interaction term between mean daily fluid balance on RRT and fluid overload. We did not consider a similar logistic regression model for RRT dependence in hospital survivors in fluid overloaded patients due to few outcome events.

Data were recorded in a Microsoft (Microsoft, Redmond, WA, USA) Access database. All analyses were done using SAS version 9.3 (SAS Institute Inc., Cary, NC, USA.) or R version 2.15.3 (The R Foundation for Statistical Computing, Vienna, Austria). All tests are two-sided; we considered $P$ $<0.05$ to be statistically significant.

\section{Ethics}

The Research Ethics Boards of St Michael's Hospital and Sunnybrook Health Sciences Centre approved this study. In view of the observational nature of the study and measures to maintain confidentiality of patient data, the requirement for individual patient consent was waived.

\section{Results}

A total of 492 patients, of whom 299 (60.8\%) were male, met criteria for inclusion in the study (Figure 1). The mean (SD) age was 62.9 (16.3) years, the mean (SD) SOFA score at ICU admission was 12.1 (4.2), and 251 (51.0\%) patients died in hospital. Of the 241 survivors, $61(25.3 \%)$ required RRT at hospital discharge. Further patient characteristics are given in Table 1. Intradialytic hypotension was common, occurring in 428 (87.3\%) of patients on one or more occasions. The median (Q1, Q3) of mean daily fluid balances over the first seven days of RRT in the entire cohort was $708(-69,1805) \mathrm{mL}$, with a positive mean fluid balance in $353(71.7 \%)$ of patients. Mean daily fluid balance differed between hospital decedents (1134 $(242,2556) \mathrm{mL})$ and survivors (413 $(-371,1106) \mathrm{mL} ; P<0.01)$, but not between survivors who were RRT dependent at hospital discharge (71 $(-330,898) \mathrm{mL})$ and those who were not $(475(-400$, 1310) $\mathrm{mL} ; P=0.36$ ). Figures 2 and 3 show daily fluid balance over time in hospital decedents vs. survivors and in survivors requiring RRT vs. free of RRT at hospital discharge, respectively.

\section{Hospital mortality}

Our main exposures of mean daily fluid balance and intradialytic hypotension were only weakly correlated

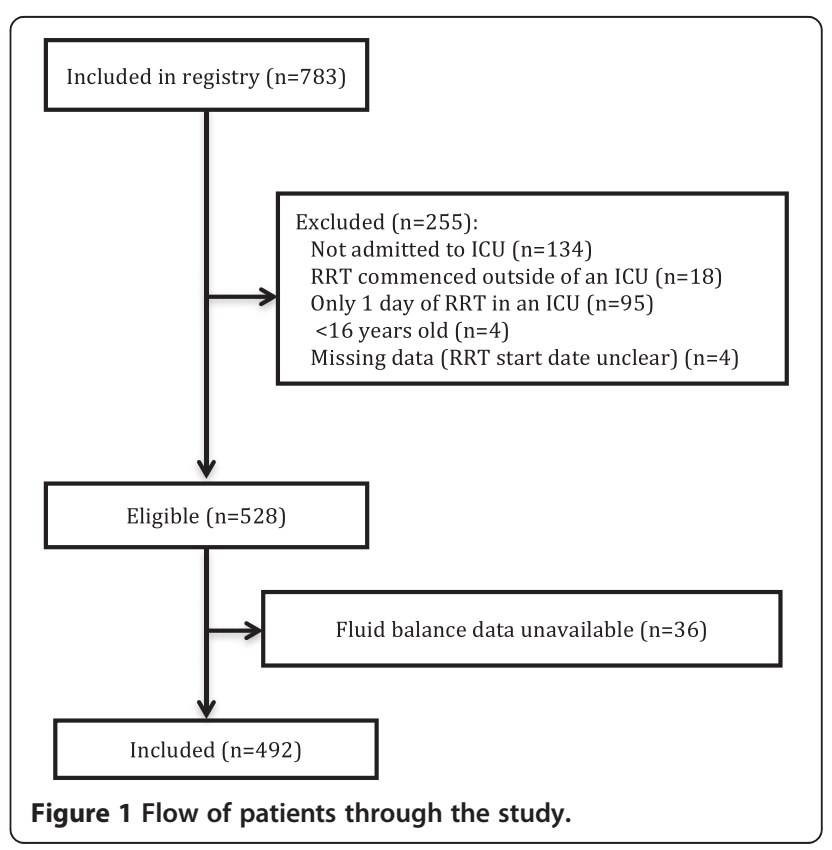


Table 1 Characteristics of patients in the cohort

\begin{tabular}{|c|c|c|c|c|}
\hline Variable & $\begin{array}{l}\text { Whole cohort } \\
(n=492)\end{array}$ & $\begin{array}{l}\text { Survivors } \\
(n=241)\end{array}$ & $\begin{array}{l}\text { Non-survivors } \\
(\mathrm{n}=251)\end{array}$ & $P$ value \\
\hline \multicolumn{5}{|l|}{ Demographics } \\
\hline Age, years & $62.9(16.3)$ & $61.0(16.6)$ & $64.7(15.7)$ & 0.01 \\
\hline Male & $299(60.8 \%)$ & $148(61.4 \%)$ & $151(60.2 \%)$ & 0.78 \\
\hline Weight, $\mathrm{kg}(\mathrm{n}=413,197,216)$ & $85.2(24.3)$ & $86.2(24.4)$ & $84.3(24.2)$ & 0.43 \\
\hline \multicolumn{5}{|l|}{ Comorbidities } \\
\hline Charlson comorbidity index & $2(1,3)$ & $2(1,3)$ & $2(1,4)$ & $<0.001$ \\
\hline Congestive heart failure & $89(18.1 \%)$ & $43(17.8 \%)$ & $46(18.3 \%)$ & 0.89 \\
\hline Liver cirrhosis & $20(4.1 \%)$ & $4(1.7 \%)$ & $16(6.4 \%)$ & 0.01 \\
\hline Baseline creatinine, $\mu \mathrm{mol} / \mathrm{L}(n=490,240,250)$ & $123.5(86,206)$ & $136.5(92,223)$ & $110(83,190)$ & $<0.001$ \\
\hline \multicolumn{5}{|l|}{ Details of ICU admission } \\
\hline \multicolumn{5}{|l|}{ Admission type } \\
\hline Medical & $241(49.0 \%)$ & $115(47.7 \%)$ & $126(50.2 \%)$ & 0.58 \\
\hline Surgical & $251(51.0 \%)$ & $126(52.3 \%)$ & $125(49.8 \%)$ & \\
\hline Cardiac surgery & $86(17.5 \%)$ & $47(19.5 \%)$ & $39(15.5 \%)$ & 0.25 \\
\hline Aortic aneurysm repair & $29(5.9 \%)$ & $19(7.9 \%)$ & $10(4.0 \%)$ & 0.07 \\
\hline Admission diagnosis $(n=485,238,247)$ & & & & $<0.001$ \\
\hline Trauma & $25(5.2 \%)$ & $15(6.3 \%)$ & $10(4.1 \%)$ & \\
\hline Cardiovascular & $198(40.8 \%)$ & $106(44.5 \%)$ & $92(37.3 \%)$ & \\
\hline Respiratory & $59(12.2 \%)$ & $24(10.1 \%)$ & $35(14.2 \%)$ & \\
\hline Gastrointestinal & $91(18.8 \%)$ & $26(10.9 \%)$ & $65(26.3 \%)$ & \\
\hline Neurological & $11(2.3 \%)$ & $6(2.5 \%)$ & $5(2.0 \%)$ & \\
\hline Renal & $54(11.1 \%)$ & $37(15.6 \%)$ & $17(6.9 \%)$ & \\
\hline Other & $47(9.7 \%)$ & $24(10.1 \%)$ & $23(9.3 \%)$ & \\
\hline SOFA on day of ICU admission $(n=347,164,183)$ & $12.1(4.2)$ & $11.6(4.2)$ & $12.5(4.1)$ & 0.05 \\
\hline SOFA - cardiovascular on day of ICU admission $(n=341,161,180)$ & $3(1,4)$ & $3(1,4)$ & $3(1,4)$ & 0.17 \\
\hline Any vasopressor use on days 1-7 & $272(55.3 \%)$ & $100(41.5 \%)$ & $172(68.5 \%)$ & $<0.001$ \\
\hline \multicolumn{5}{|l|}{ Details of RRT } \\
\hline SOFA on day RRT commenced $(n=490,239,251)$ & $14.2(4.2)$ & $12.8(3.9)$ & $15.6(4.1)$ & $<0.001$ \\
\hline SOFA - cardiovascular on day RRT commenced $(n=490,239,251)$ & $3(1,4)$ & $3(1,4)$ & $4(2,4)$ & $<0.001$ \\
\hline Days from ICU admission to RRT & $2(1,5.5)$ & $2(1,4)$ & $2(1,7)$ & 0.002 \\
\hline Initial RRT modality & & & & $<0.001$ \\
\hline IHD & $212(43.1 \%)$ & $129(53.5 \%)$ & $83(33.1 \%)$ & \\
\hline SLED & $61(12.4 \%)$ & $31(12.9 \%)$ & $30(12.0 \%)$ & \\
\hline CRRT & $219(44.5 \%)$ & $81(33.6 \%)$ & $138(55.0 \%)$ & \\
\hline Days of RRT & $7(4,13)$ & $7(4,14)$ & $6(3,12)$ & 0.015 \\
\hline Mean daily fluid balance, $\mathrm{mL}$ & $708(-69,1805)$ & $413(-371,1106)$ & $1134(242,2556)$ & $<0.001$ \\
\hline Positive mean daily fluid balance on days 1-7 & $353(71.7 \%)$ & $151(62.7 \%)$ & $202(80.5 \%)$ & $<0.001$ \\
\hline Intradialytic hypotension on any day $(n=490,240,250)$ & $428(87.3 \%)$ & $194(80.8 \%)$ & $234(93.6 \%)$ & $<0.001$ \\
\hline Intradialytic hypotension (\% days up to 7 ) ( $n=490,240,250)$ & $50.0(28.6,80.0)$ & $42.9(20.0,66.7)$ & $66.7(42.9,100)$ & $<0.001$ \\
\hline
\end{tabular}


Table 1 Characteristics of patients in the cohort (Continued)

\begin{tabular}{|c|c|c|c|c|}
\hline \multicolumn{5}{|l|}{ Clinical outcomes } \\
\hline Days of ICU stay & $14(7,26.5)$ & $14(7,29)$ & $14(8,24)$ & 0.75 \\
\hline Days of hospital stay & $28(15.5,48)$ & $34(23,58)$ & $21(11,39)$ & $<0.001$ \\
\hline
\end{tabular}

Dichotomous data are of the form $\mathrm{n}(\%)$ and continuous data of the form mean (SD) or median (Q1, Q3). The number of patients with data is provided where this differs from the total. $P$ values are based on univariable logistic regression, except for days of ICU and hospital stay, days between ICU admission and RRT, and days of RRT, for which Wilcoxon signed-rank tests are reported. CRRT, continuous renal replacement therapy; ICU, intensive care unit; IHD, intermittent hemodialysis; RRT, renal replacement therapy; SLED, sustained low-efficiency dialysis; SOFA, sequential organ failure assessment score.

(Spearman's correlation 0.23). In our final multivariable logistic regression model (Table 2), independent risk factors for mortality included mean daily fluid balance (OR 1.36 per $1000 \mathrm{~mL}$ more positive, 95\% CI 1.18 to 1.57 ), intradialytic hypotension (OR 1.14 per $10 \%$ increase in number of days with intradialytic hypotension, 95\% CI 1.06 to 1.23 ), higher age (OR 1.15 per 5 years, 95\% CI 1.07 to 1.25$)$, higher Charlson comorbidity index (OR 1.28, 95\% CI 1.14 to 1.44 ), and higher maximum
SOFA score (OR 1.21, 95\% CI 1.13 to 1.29 ) on days 1 to 7 of RRT were associated with increased mortality, while higher baseline creatinine (OR 0.98 per $10 \mu \mathrm{mol} / \mathrm{l}$, 95\% CI 0.97 to 0.996 ) was associated with lower mortality. These findings were similar in a sensitivity analysis adjusting for number of days with fluid balance available (OR per $1000 \mathrm{~mL}$ mean daily fluid balance 1.41, 95\% CI 1.22 to 1.63 ; OR per $10 \%$ increase in days of intradialytic hypotension $1.16,95 \%$ CI 1.02 to 1.32 ). Multiple logistic

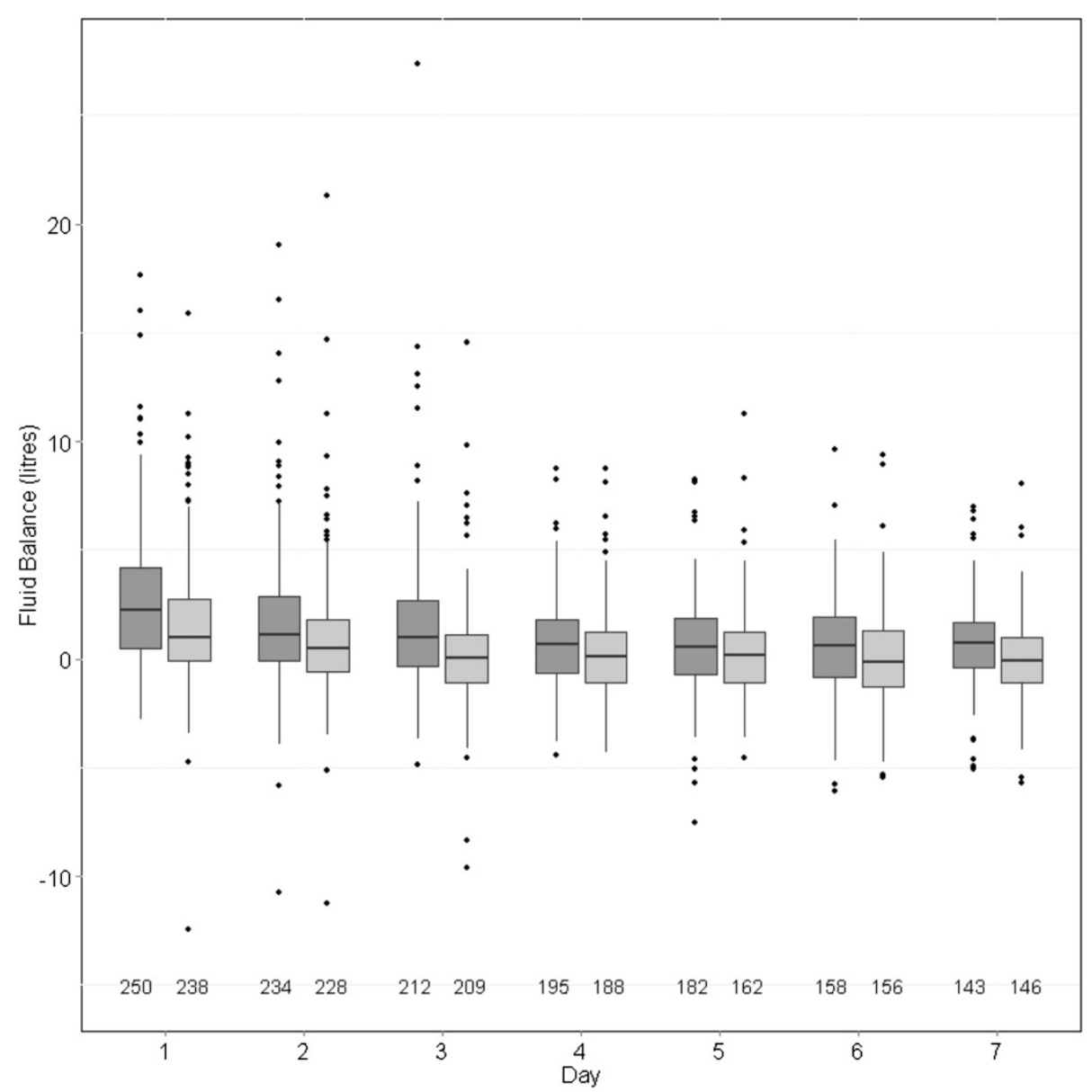

Figure 2 Fluid balance on each of the first seven days after starting renal replacement therapy (RRT), in decedents at hospital discharge (dark grey) vs. survivors (light grey). The number of patients with data is below each column. For each column, the dark horizontal line denotes the median value, the bottom and top of the box denote the first and third quartiles respectively, the upper whisker extends to the highest value that is within $(1.5 \times$ interquartile range) of the third quartile, and the lower whisker extends to the lowest value within $(1.5 \times$ interquartile range) of the first quartile. Data beyond the end of the whiskers are outliers and plotted as points. 


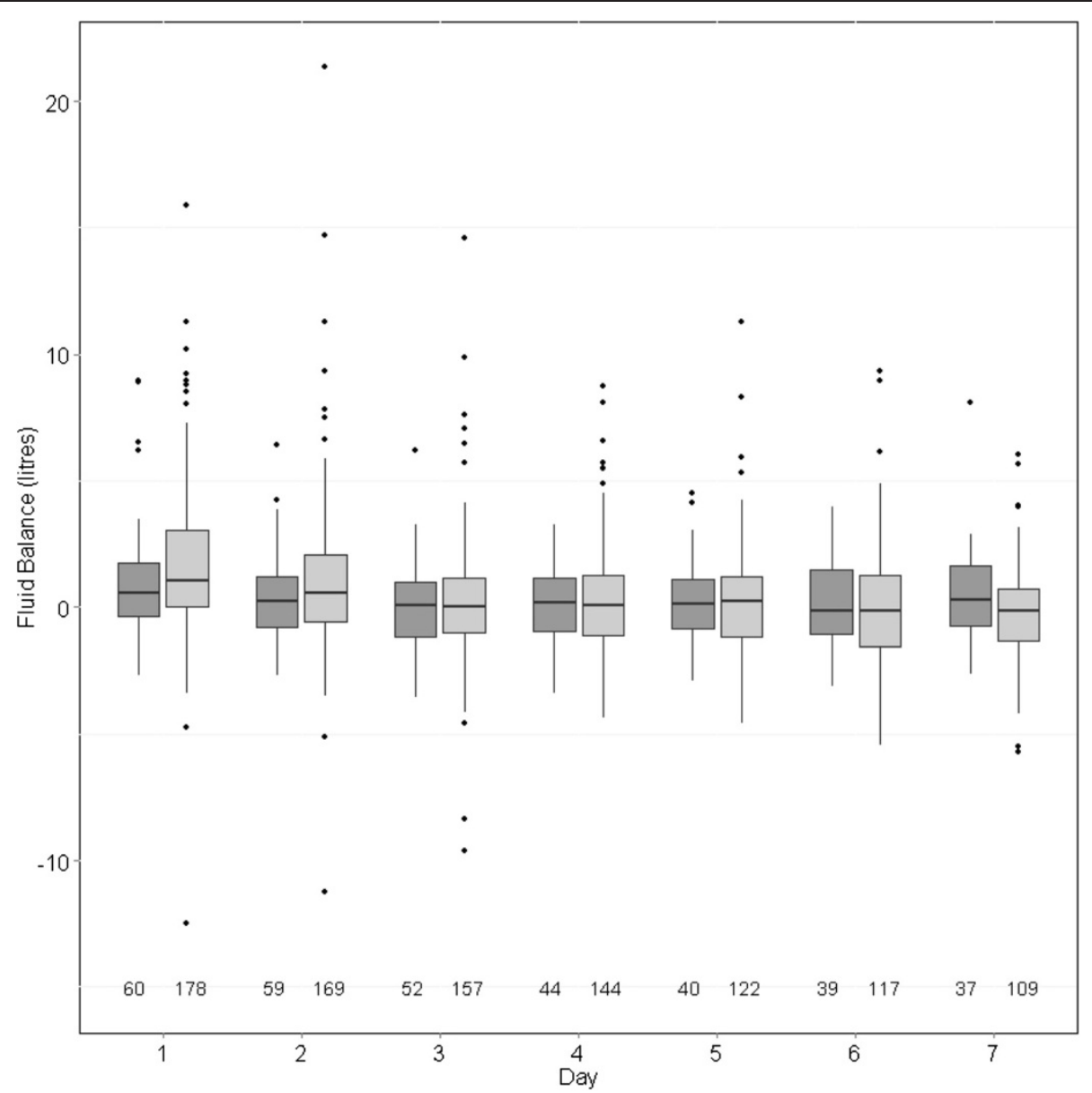

Figure 3 Fluid balance on each of the first seven days after starting renal replacement therapy (RRT), in survivors to hospital discharge in patients who were RRT dependent (dark grey) vs. RRT free (light grey). The number of patients with data is below each column. For each column, the dark horizontal line denotes the median value, the bottom and top of the box denote the first and third quartiles, the upper whisker extends to the highest value that is within $(1.5 \times$ interquartile range) of the third quartile, and the lower whisker extends to the lowest value within $(1.5 \times$ interquartile range) of the first quartile. Data beyond the end of the whiskers are outliers and plotted as points.

regression with fluid balance dichotomised gave similar results: adjusted OR for positive vs. negative mean daily fluid balance $1.72,95 \%$ CI 1.06 to 2.81 .

\section{RRT dependence in hospital survivors}

Univariable comparisons are given in Additional file 1. Our main exposures of mean daily fluid balance and intradialytic hypotension were not strongly correlated (Spearman's correlation 0.06). In our final model (Table 3), neither mean daily fluid balance (OR 0.93 per $1000 \mathrm{~mL}, 95 \%$ CI 0.75 to 1.16) nor intradialytic hypotension (OR 1.02 per $10 \%$ increase in number of days with intradialytic hypotension, 95\% CI 0.92 to 1.13 ) were associated with RRT dependence at hospital discharge; the only independent predictor was a pre-existing diagnosis of congestive heart failure (OR 3.13, 95\% CI 1.46 to 6.74). A sensitivity analysis using multiple logistic regression with fluid balance dichotomised gave similar results: adjusted OR for positive vs. negative mean daily fluid balance $0.72,95 \%$ CI 0.38 to 1.35 .
Interaction of fluid overload at RRT commencement and mean daily fluid balance on RRT

Three hundred and eight (62.6\%) patients in the cohort had sufficient data to calculate fluid overload at the start of RRT; of those, 125 (40.6\%) had $>10 \%$ fluid overload. Compared to patients without fluid overload, those with $>10 \%$ fluid overload (Additional file 2) weighed less on admission, had lower baseline creatinine, had different admission diagnoses, started RRT later in the ICU admission and with more organ dysfunction, and were more likely to die in hospital. In this subgroup of patients for whom fluid overload was calculable, $>10 \%$ fluid overload at commencement of RRT was associated with mortality (adjusted OR 2.03, 95\% CI 1.12 to 3.68), but only weakly correlated with mean daily fluid balance (Spearman's coefficient 0.03). There was no interaction between the effects of fluid overload and mean daily fluid balance (interaction $P=0.72$ ). The associations between mortality and the main exposures of mean daily 
Table 2 Final multiple logistic regression model for mortality

\begin{tabular}{|c|c|c|c|c|}
\hline Variable & $\begin{array}{l}\text { Unadjusted OR } \\
(95 \% \mathrm{Cl})\end{array}$ & $P$ value & $\begin{array}{l}\text { Adjusted OR } \\
(95 \% \mathrm{Cl})\end{array}$ & $P$ value \\
\hline Mean daily fluid balance (per $1000 \mathrm{~mL}$ positive) & $1.47(1.30-1.66)$ & $<0.001$ & $1.36(1.18-1.57)$ & $<0.001$ \\
\hline Intradialytic hypotension (per 10\% increase in number of days) & $1.27(1.19-1.35)$ & $<0.001$ & $1.14(1.06-1.23)$ & $<0.001$ \\
\hline Age (per 5-year increase) & $1.07(1.02-1.14)$ & 0.01 & $1.15(1.07-1.25)$ & $<0.001$ \\
\hline Male sex & $0.95(0.66-1.36)$ & 0.78 & $1.04(0.66-1.64)$ & 0.85 \\
\hline Charlson comorbidity index & $1.16(1.07-1.26)$ & $<0.001$ & $1.28(1.14-1.44)$ & $<0.001$ \\
\hline Primary renal diagnosis & $0.44(0.24-0.78)$ & 0.005 & $0.82(0.40-1.66)$ & 0.58 \\
\hline Baseline creatinine (per $10 \mu \mathrm{mol} / \mathrm{l}$ increase) & $0.98(0.97-0.99)$ & $<0.001$ & $0.98(0.97-0.996)$ & 0.01 \\
\hline Abdominal aortic aneurysm repair & $0.48(0.22-1.07)$ & 0.07 & $0.52(0.20-1.36)$ & 0.18 \\
\hline Maximum SOFA on days 1-7 & $1.22(1.16-1.28)$ & $<0.001$ & $1.21(1.13-1.29)$ & $<0.001$ \\
\hline Any vasopressors on days 1-7 & $3.07(2.12-4.44)$ & $<0.001$ & $1.58(0.96-2.62)$ & 0.07 \\
\hline \multicolumn{5}{|l|}{ Initial RRT modality } \\
\hline CRRT vs. IHD & $2.65(1.79-3.91)$ & $<0.001$ & $0.59(0.34-1.02)$ & 0.06 \\
\hline SLED vs. IHD & $1.50(0.85-2.67)$ & 0.16 & $0.69(0.34-1.40)$ & 0.30 \\
\hline
\end{tabular}

The final model had 492 patients and 251 deaths; it did not demonstrate lack of goodness of fit (Hosmer-Lemeshow $P=0.85$ ). $\mathrm{Cl}$, confidence interval; CRRT, continuous renal replacement therapy; IHD, intermittent hemodialysis; OR, odds ratio; RRT, renal replacement therapy; SLED, sustained low-efficiency dialysis; SOFA, sequential organ failure assessment score.

fluid balance (adjusted OR 1.53 per $1000 \mathrm{~mL}, 95 \%$ CI 1.25 to 1.87 ) and intradialytic hypotension (1.18 per $10 \%$ increase in number of days with intradialytic hypotension, 95\% CI 1.06 to 1.31 ) remained similar to the original model (Table 4).

\section{Discussion}

In this large and heterogeneous cohort of critically ill patients with AKI who received RRT, a more positive mean daily fluid balance and intradialytic hypotension in the week after RRT initiation were independently associated with an increased risk of hospital mortality, but not RRT dependence at hospital discharge in survivors. Fluid overload at commencement of RRT was associated with mortality in this cohort, as in previous studies [4,8-10]. However, our main focus was on mean daily fluid balance in the week after RRT initiation, taking into account the risk of intradialytic hypotension with fluid removal, which we believed to be a clinically relevant variable with important therapeutic implications. The initiation of RRT brings with it the opportunity for clinicians to proactively and rigorously control fluid balance with relative ease, and thus the influence of fluid management on clinical outcomes has important implications for both the timing and goals of RRT.

Table 3 Final multiple logistic regression model for RRT dependence at hospital discharge in survivors.

\begin{tabular}{|c|c|c|c|c|}
\hline Variable & $\begin{array}{l}\text { Unadjusted OR } \\
(95 \% \mathrm{Cl})\end{array}$ & $P$ value & $\begin{array}{l}\text { Adjusted OR } \\
(95 \% \mathrm{Cl})\end{array}$ & $P$ value \\
\hline Mean daily fluid balance (per $1000 \mathrm{~mL}$ positive) & $0.91(0.74-1.12)$ & 0.36 & $0.93(0.75-1.16)$ & 0.54 \\
\hline Intradialytic hypotension (per $10 \%$ increase in number of days) & $1.01(0.92-1.11)$ & 0.86 & $1.02(0.92-1.13)$ & 0.69 \\
\hline Male sex & $1.05(0.58-1.91)$ & 0.87 & $1.20(0.62-2.31)$ & 0.59 \\
\hline Congestive heart failure & $2.60(1.30-5.19)$ & 0.007 & $3.13(1.46-6.74)$ & 0.003 \\
\hline Medical (versus surgical) diagnosis & $1.84(1.02-3.32)$ & 0.04 & $1.75(0.88-3.47)$ & 0.11 \\
\hline Primary renal diagnosis & $2.02(0.97-4.23)$ & 0.06 & $1.72(0.75-3.94)$ & 0.20 \\
\hline Baseline creatinine (per $10 \mu \mathrm{mol} / \mathrm{l}$ increase) & $1.01(0.999-1.02)$ & 0.07 & $1.01(0.995-1.02)$ & 0.23 \\
\hline Maximum SOFA on days 1-7 & $0.94(0.87-1.01)$ & 0.10 & $0.98(0.89-1.07)$ & 0.65 \\
\hline \multicolumn{5}{|l|}{ Initial RRT modality } \\
\hline CRRT vs. IHD & $0.52(0.26-1.04)$ & 0.06 & $0.72(0.31-1.65)$ & 0.43 \\
\hline SLED vs. IHD & $1.18(0.51-2.75)$ & 0.70 & $1.51(0.60-3.83)$ & 0.38 \\
\hline
\end{tabular}

The final model had 241 survivors and 61 patients with RRT dependence at hospital discharge; it did not demonstrate lack of goodness of fit (Hosmer-Lemeshow $P=0.69$ ). $\mathrm{Cl}$, confidence interval; $\mathrm{CRRT}$, continuous renal replacement therapy; IHD, intermittent hemodialysis; $\mathrm{OR}$, odds ratio; RRT, renal replacement therapy; SLED, sustained low-efficiency dialysis; SOFA, sequential organ failure assessment score. 


\begin{tabular}{|c|c|c|c|c|}
\hline Variable & $\begin{array}{l}\text { Unadjusted OR } \\
(95 \% \mathrm{Cl})\end{array}$ & $P$ value & $\begin{array}{l}\text { Adjusted OR } \\
(95 \% \mathrm{Cl})\end{array}$ & $P$ value \\
\hline Mean daily fluid balance (per $1000 \mathrm{~mL}$ positive) & $1.67(1.40-1.99)$ & $<0.001$ & $1.53(1.25-1.87)$ & $<0.001$ \\
\hline Intradialytic hypotension (per 10\% increase in number of days) & $1.31(1.21-1.43)$ & $<0.001$ & $1.18(1.06-1.31)$ & 0.002 \\
\hline Fluid overload $>10 \%$ vs. $\leq 10 \%$ & $2.27(1.42-3.64)$ & 0.006 & $2.03(1.12-3.68)$ & 0.02 \\
\hline Age (per 5-year increase) & $1.04(0.98-1.12)$ & 0.21 & $1.11(1.01-1.22)$ & 0.02 \\
\hline Male sex & $0.94(0.59-1.48)$ & 0.78 & $1.14(0.64-2.04)$ & 0.66 \\
\hline Charlson comorbidity index & $1.09(0.98-1.21)$ & 0.10 & $1.21(1.05-1.39)$ & 0.01 \\
\hline Abdominal aortic aneurysm repair & $0.55(0.23-1.34)$ & 0.19 & $0.65(0.22,1.96)$ & 0.44 \\
\hline Primary renal diagnosis & $0.55(0.27-1.13)$ & 0.10 & $1.31(0.53-3.26)$ & 0.56 \\
\hline Baseline creatinine (per $10 \mu \mathrm{mol} / \mathrm{l}$ increase) & $0.97(0.96-0.99)$ & 0.003 & $0.99(0.97-1.01)$ & 0.24 \\
\hline Maximum SOFA on days 1-7 & $1.24(1.16-1.32)$ & $<0.001$ & $1.15(1.05-1.26)$ & 0.002 \\
\hline Any vasopressors on days 1-7 & $3.37(2.07-5.46)$ & $<0.001$ & $1.52(0.78-2.95)$ & 0.22 \\
\hline \multicolumn{5}{|l|}{ Initial RRT modality } \\
\hline CRRT vs. IHD & $3.11(1.89,5.11)$ & $<0.001$ & $0.77(0.39-1.52)$ & 0.45 \\
\hline SLED vs. IHD & $1.18(0.56,2.51)$ & 0.66 & $0.51(0.20-1.32)$ & 0.16 \\
\hline
\end{tabular}

The final model had 308 patients and 168 deaths; it did not demonstrate lack of goodness of fit (Hosmer Lemeshow $P=0.62$ ). There was no evidence of interaction between mean daily fluid balance and fluid overload $(P=0.72)$; we therefore report the results of the model with no interaction term. $\mathrm{Cl}$, confidence interval; CRRT, continuous renal replacement therapy; IHD, intermittent hemodialysis; OR, odds ratio; RRT, renal replacement therapy; SLED, sustained low-efficiency dialysis; SOFA, sequential organ failure assessment score.

Biological mechanisms have been proposed linking fluid overload to disruption of the endothelial glycocalyx, interstitial edema, multiple organ damage, and death $[20,21]$. Limited support for the injurious effects of fluid overload on renal and other organ function comes from secondary analyses of two large randomised trials. One study found a negative mean daily fluid balance to be associated with lower 90-day mortality and increased RRT-free days in a large trial of high- vs. low-dose RRT for AKI [4], and another found a lower incidence of AKI in patients with acute respiratory distress syndrome randomized to a restrictive vs. liberal fluid management group, after correction for the dilutional effect of a positive fluid balance [22]. These associations between less fluid accumulation and improved outcomes suggest that clinicians may consider ultrafiltration to minimise or remove accumulated fluid once patients commence RRT.

We hypothesised that limiting or removing fluid overload after patients commenced RRT for AKI may ameliorate AKI severity and improve renal recovery in survivors. Although we found that a more positive fluid balance on RRT was associated with mortality, there was no association with RRT dependence at hospital discharge. Unsurprisingly, we found that intradialytic hypotension was associated with mortality. However, despite evidence that relative hypotension is associated with AKI onset in a non-critically ill hospital population [23], we found no association between intradialytic hypotension and RRT dependence. Although this finding may arise from lack of statistical power, another possible interpretation is that mild hypotension in the course of fluid removal may not reduce the probability of renal recovery in patients who survive.

Our study adds to current understanding of the relationship between fluid balance and outcomes. While previous studies have demonstrated an association between fluid overload at selected time points and death, ours is only the second study after that of Bellomo et al. [4] to demonstrate the relationship between positive fluid balance on RRT and mortality in critically ill adults, and suggests that fluid management during RRT is an important target for future clinical trials. Our sensitivity analysis adjusting for fluid accumulation at RRT initiation suggests that this relationship is not confined to those with measured fluid overload. Our cohort comprises a heterogeneous and unselected sample of critically ill patients for whom clinicians made the decision to start RRT, and demonstrates the safety of a less positive fluid management strategy.

The main limitation of this and previous similar studies is that risk adjustment cannot eliminate the possibility of residual confounding. While we adjusted for confounders such as severity of physiological derangement (SOFA score), premorbid health (Charlson comorbidity index), cardiovascular instability (use of vasopressors and intradialytic hypotension), and age, we lacked data on fluid overload at the time of RRT initiation in $40 \%$ of the cohort and therefore could not adjust for this covariate without a substantial 
loss of statistical power. However, sensitivity analysis in patients in whom fluid overload was calculable produced similar results to that in the whole cohort. It is also possible that other unknown confounders influenced both fluid requirements and the outcomes of mortality and RRT dependence in survivors. Immortal time bias was also a potential problem; however, a sensitivity analysis that accounted for the number of days with data available did not materially alter our findings. Residual confounding may have contributed to the surprising findings that higher baseline creatinine was associated with lower risk of death, but not with RRT dependence at discharge. These associations may reflect the occurrence of RRT-dependent AKI with less severe systemic illness among patients with pre-existing chronic kidney disease.

Other important limitations relating to the observational nature of this study include the lack of standardised criteria for the initiation of and management of RRT, leading to fluid overload as the primary indication for RRT in some patients, the lack of data on the relative contribution of intake and output to overall fluid balance, and missing data. Other limitations of data restricted the calculation of fluid balance to the first seven days following RRT initiation. Although the endpoints of mortality and RRT dependence at hospital discharge are clinically important, some patients may have been transferred to other acute care hospitals, with less certainly regarding final disposition. We defined intradialytic hypotension to include both absolute and relative hypotension and considered the frequency as a percentage of the total number of RRT sessions during which it occurred. However, similar to other AKI studies that reported details of hypotension [23], we lacked data on the duration of each episode and the frequency within individual RRT sessions. Finally, our study included data from only two hospitals, limiting applicability to other centres.

\section{Conclusions}

In summary, our study provides supportive evidence for reduced mortality with a less positive fluid balance after critically ill patients commence RRT. A less positive fluid management strategy does not appear to influence RRT dependence at hospital discharge. Further multicentre cohort investigations, if confirming these findings, would support the design of a randomized trial of an aggressive vs. less aggressive approach to fluid removal in this population.

\section{Key messages}

- A more positive fluid balance and intradialytic hypotension are associated with increased risk of death in a cohort of critically ill patients undergoing renal replacement therapy
- Fluid balance and intradialytic hypotension are not associated with requirement for renal replacement therapy at the time of hospital discharge

- Clinicians may consider using ultrafiltration to minimise fluid overload in critically ill patients with acute kidney injury receiving renal replacement therapy

\section{Additional files}

Additional file 1: Distribution of risk factors and outcomes for renal replacement therapy (RRT) dependence at hospital discharge in survivors. Description: This table shows the distribution of risk factors, with $P$ values, between groups of hospital survivors after commencement of RRT who were dependent on RRT vs. not at time of discharge.

Additional file 2: Patient characteristics and outcomes for subgroups with missing data, and those with and without $>10 \%$ fluid overload at renal replacement therapy (RRT) initiation.

\section{Abbreviations}

AKI: acute kidney injury; Cl: confidence interval; CRRT: continuous renal replacement therapy; ICU: intensive care unit; IHD: intermittent hemodialysis; MAP: mean arterial pressure; OR: odds ratio; RRT: renal replacement therapy; SD: standard deviation; SLED: sustained low-efficiency dialysis;

SOFA: sequential organ failure assessment.

\section{Competing interests}

The authors declare that they have no competing interests.

\section{Authors' contributions}

JS conceived of the study, participated in design and co-ordination, and drafted and revised the manuscript. RP performed the statistical analyses and helped to draft and revise the manuscript. RK undertook collection of data. RW conceived of and co-ordinated the registry, participated in study conduct and helped to draft the manuscript. $\mathrm{MH}$ participated in study conduct and helped to draft the manuscript. SL participated in co-ordination of the study and helped to draft the manuscript. NA participated in design and co-ordination of the study, participated in study conduct, supervised the statistical analyses, and drafted and revised the manuscript. All authors read and approved the final manuscript.

\section{Acknowledgements}

We thank Victor Perkins for assistance in collection of data.

\section{Author details}

${ }^{1}$ Interdepartmental Division of Critical Care, University of Toronto, 30 Bond Street, Toronto, ON M5B 1W8, Canada. ${ }^{2}$ Centre for Infection and Immunity, Queens University Belfast, Health Sciences Building, 97 Lisburn Road, Belfast BT9 7BL, UK. ${ }^{3}$ Division of Critical Care and Outreach, Belfast Health and Social Care Trust, Belfast City Hospital, Lisburn Road, Belfast BT9 7AB, UK

${ }^{4}$ Programme in Trauma, Emergency, and Critical Care, Sunnybrook Health Sciences Centre, Room D1.08, 2075 Bayview Avenue, Toronto, ON M4N 3M5, Canada. ${ }^{5}$ Division of Nephrology, St Michael's Hospital, 30 Bond Street, Toronto, ON M5B 1W8, Canada. ${ }^{6}$ Division of Nephrology, University of Toronto, 190 Elizabeth Street, Suite 3-805, Toronto, ON M5G 2C4, Canada. ${ }^{7}$ Division of Nephrology, Sunnybrook Health Sciences Centre, 2075 Bayview Avenue, Room A206a, Toronto, ON M4N 3M5, Canada. ${ }^{8}$ Department of Critical Care Medicine, Sunnybrook Health Sciences Centre, Room D1.08, 2075 Bayview Avenue, Toronto, ON M4N 3M5, Canada.

Received: 5 March 2014 Accepted: 28 October 2014 Published online: 18 November 2014

\section{References}

1. Nisula S, Kaukonen K-M, Vaara ST, Korhonen A-M, Poukkanen M, Karlsson S, Haapio M, Inkinen O, Parviainen I, Suojaranta-Ylinen R, Laurila JJ, Tenhunen J, Reinikainen M, Ala-Kokko T, Ruokonen E, Kuitunen A, Pettilä V, FINNAKI Study Group: Incidence, risk factors and 90-day mortality of patients with 
acute kidney injury in Finnish intensive care units: the FINNAKI study. Intensive Care Med 2013, 39:420-428.

2. Uchino S, Kellum JA, Bellomo R, Doig GS, Morimatsu H, Morgera S, Schetz M, Tan I, Bouman C, Macedo E, Gibney N, Tolwani A, Ronco C, Beginning and Ending Supportive Therapy for the Kidney (BEST Kidney) Investigators: Acute renal failure in critically ill patients: a multinational, multicenter study. JAMA 2005, 294:813-818.

3. Metnitz PGH, Krenn CG, Steltzer H, Lang T, Ploder J, Lenz K, Le Gall J-R, Druml W: Effect of acute renal failure requiring renal replacement therapy on outcome in critically ill patients. Crit Care Med 2002, 30:2051-2058.

4. Bellomo R, Cass A, Cole L, Finfer S, Gallagher M, Lee J, Lo S, McArthur C, McGuiness S, Norton R, Myburgh J, Scheinkestel C, Su S: An observational study fluid balance and patient outcomes in the randomized evaluation of normal vs. augmented level of replacement therapy trial. Crit Care Med 2012, 40:1753-1760.

5. Sladen RN: Oliguria in the ICU. Systematic approach to diagnosis and treatment. Anesthesiol Clin North America 2000, 18:739-752. viii.

6. Langenberg C, Bellomo R, May C, Wan L, Egi M, Morgera S: Renal blood flow in sepsis. Crit Care 2005, 9:R363-R374.

7. Schnell D, Camous L, Guyomarc'h S, Duranteau J, Canet E, Gery P, Dumenil A-S, Zeni F, Azoulay E, Darmon M: Renal perfusion assessment by renal Doppler during fluid challenge in sepsis. Crit Care Med 2013, 41:1214-1220.

8. Vaara ST, Korhonen A-M, Kaukonen K-M, Nisula S, Inkinen O, Hoppu S, Laurila JJ, Mildh L, Reinikainen M, Lund V, Parviainen I, Pettilä V: Fluid overload is associated with an increased risk for 90-day mortality in critically ill patients with renal replacement therapy: data from the prospective FINNAKI study. Crit Care 2012, 16:R197.

9. Payen D, de Pont AC, Sakr Y, Spies C, Reinhart K, Vincent JL, Sepsis Occurrence in Acutely III Patients (SOAP) Investigators: A positive fluid balance is associated with a worse outcome in patients with acute renal failure. Crit Care 2008, 12:R74.

10. Bouchard J, Soroko SB, Chertow GM, Himmelfarb J, Ikizler TA, Paganini EP, Mehta RL, Program to Improve Care in Acute Renal Disease (PICARD) Study Group: Fluid accumulation, survival and recovery of kidney function in critically ill patients with acute kidney injury. Kidney Int 2009, 76:422-427.

11. Sutherland SM, Zappitelli M, Alexander SR, Chua AN, Brophy PD, Bunchman TE, Hackbarth R, Somers MJG, Baum M, Symons JM, Flores FX, Benfield M, Askenazi D, Chand D, Fortenberry JD, Mahan JD, McBryde K, Blowey D, Goldstein SL: Fluid overload and mortality in children receiving continuous renal replacement therapy: the prospective pediatric continuous renal replacement therapy registry. Am J Kidney Dis 2010, 55:316-325.

12. Selewski DT, Cornell TT, Blatt NB, Han YY, Mottes T, Kommareddi M, Gaies MG, Annich GM, Kershaw DB, Shanley TP, Heung M: Fluid overload and fluid removal in pediatric patients on extracorporeal membrane oxygenation requiring continuous renal replacement therapy. Crit Care Med 2012, 40:2694-2699.

13. Dellinger RP, Levy MM, Rhodes A, Annane D, Gerlach H, Opal SM, Sevransky JE, Sprung CL, Douglas IS, Jaeschke R, Osborn TM, Nunnally ME, Townsend SR, Reinhart K, Kleinpell RM, Angus DC, Deutschman CS, Machado FR, Rubenfeld GD, Webb S, Beale RJ, Vincent JL, Moreno R, Surviving Sepsis Campaign Guidelines Committee including The Pediatric Subgroup: Surviving Sepsis Campaign: international guidelines for management of severe sepsis and septic shock. Intensive Care Med 2013, 2012:165-228.

14. Bagshaw S, Bellomo R: Fluid resuscitation and the septic kidney. Curr Opin Crit Care 2006, 12:527-530.

15. Fieghen HE, Friedrich JO, Burns KE, Nisenbaum R, Adhikari NK, Hladunewich MA, Lapinsky SE, Richardson RM, Wald R, University of Toronto Acute Kidney Injury Research Group: The hemodynamic tolerability and feasibility of sustained low efficiency dialysis in the management of critically ill patients with acute kidney injury. BMC Nephrol 2010, 11:32.

16. Vincent JL, Moreno R, Takala J, Willatts S, De Mendonça A, Bruining H, Reinhart CK, Suter PM, Thijs LG: The SOFA (Sepsis-related Organ Failure Assessment) score to describe organ dysfunction/failure. On behalf of the Working Group on Sepsis-Related Problems of the European Society of Intensive Care Medicine. Intensive Care Med 1996, 22:707-710.

17. Lee K, Hong SB, Lim CM, Koh Y: Sequential organ failure assessment score and comorbidity: valuable prognostic indicators in chronically critically ill patients. Anaesth Intensive Care 2008, 36:528-534.
18. Suissa S: Immortal time bias in pharmaco-epidemiology. Am J Epidemiol 2008, 167:492-499.

19. van Walraven C, Davis D, Forster AJ, Wells GA: Time-dependent bias was common in survival analyses published in leading clinical journals. J Clin Epidemiol 2004, 57:672-682.

20. Prowle JR, Echeverri JE, Ligabo EV, Ronco C, Bellomo R: Fluid balance and acute kidney injury. Nat Rev Nephrol 2009, 6:107-115.

21. Strunden MS, Heckel K, Goetz AE, Reuter DA: Perioperative fluid and volume management: physiological basis, tools and strategies. Ann Intensive Care 2011, 1:2.

22. Liu KD, Thompson BT, Ancukiewicz M, Steingrub JS, Douglas IS, Matthay MA, Wright P, Peterson MW, Rock P, Hyzy RC, Anzueto A, Truwit JD, for the National Institutes of Health National Heart, Lung and Blood Institute Acute Respiratory Distress Syndrome Network: Acute kidney injury in patients with acute lung injury: Impact of fluid accumulation on classification of acute kidney injury and associated outcomes. Crit Care Med 2011, 39:2665-2671.

23. Liu YL, Prowle J, Licari E, Uchino S, Bellomo R: Changes in blood pressure before the development of nosocomial acute kidney injury. Nephrol Dial Transplant 2009, 24:504-511.

\section{doi:10.1186/s13054-014-0624-8}

Cite this article as: Silversides et al.: Fluid balance, intradialytic hypotension, and outcomes in critically ill patients undergoing renal replacement therapy: a cohort study. Critical Care 2014 18:624.

\section{Submit your next manuscript to BioMed Central and take full advantage of:}

- Convenient online submission

- Thorough peer review

- No space constraints or color figure charges

- Immediate publication on acceptance

- Inclusion in PubMed, CAS, Scopus and Google Scholar

- Research which is freely available for redistribution

Submit your manuscript at www.biomedcentral.com/submit
C Biomed Central 